\title{
Validation of the Homeostatic Model Assessment (HOMA) of beta cell function in pancreas transplantation
}

\author{
Barnes J, Franklin R, Sharples E, James T, Friend P, Gough S, Levy J, Mittal S
}

INTRODUCTION

- Pancreas 5 year graft survival remains low

- There are no validated biomarkers of early graft dysfunction

\section{HOMA}

- Combines modelling of glucose and insulin dose response curves in all tissues

- Can quantify beta-cell function (B) and insulin sensitivity (S) in patients with diabetes

- Requires fasting glucose/insulin/c-peptide

- Relies on portal venous insulin delivery

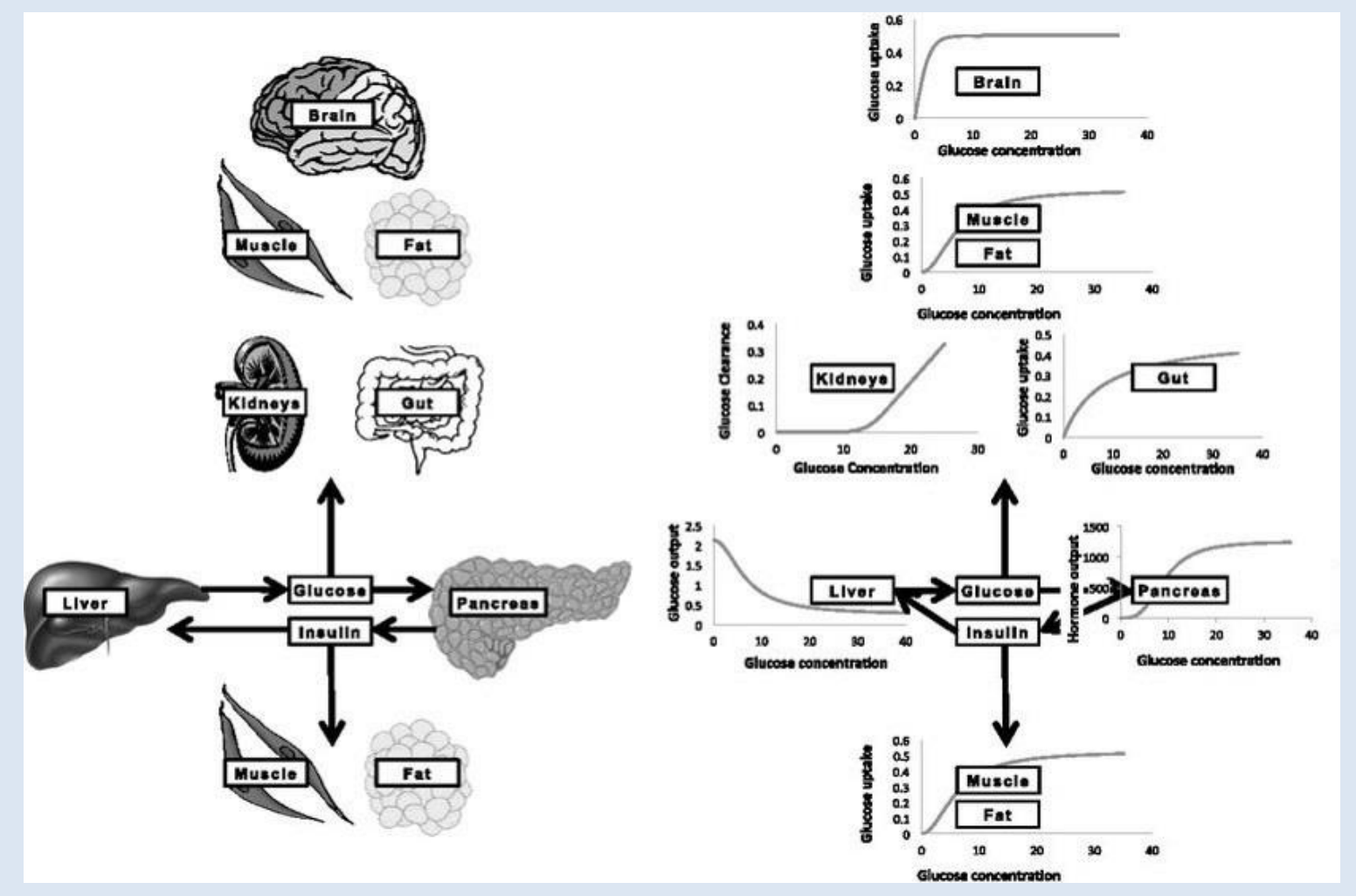

AIMS

- To develop and validate a HOMATx model for use in pancreas transplantation

\section{MeTHODS}

- HOMATx created to allow for post-hepatic insulin delivery from pancreas graft

- 12 pancreas Tx patients \& 12 matched controls

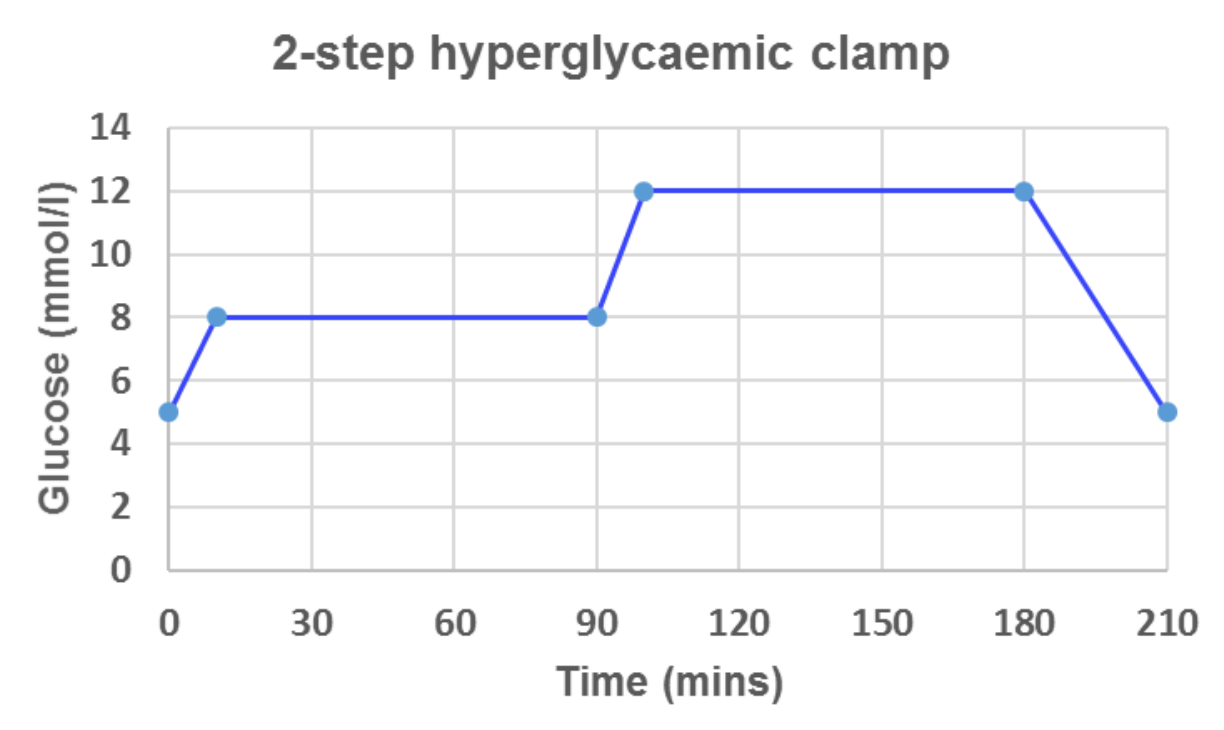

- Fasting B and S calculated from HOMATx and correlated with clamp insulin \& C-peptide

\section{RESULTS}

Table 1: Patient demographics

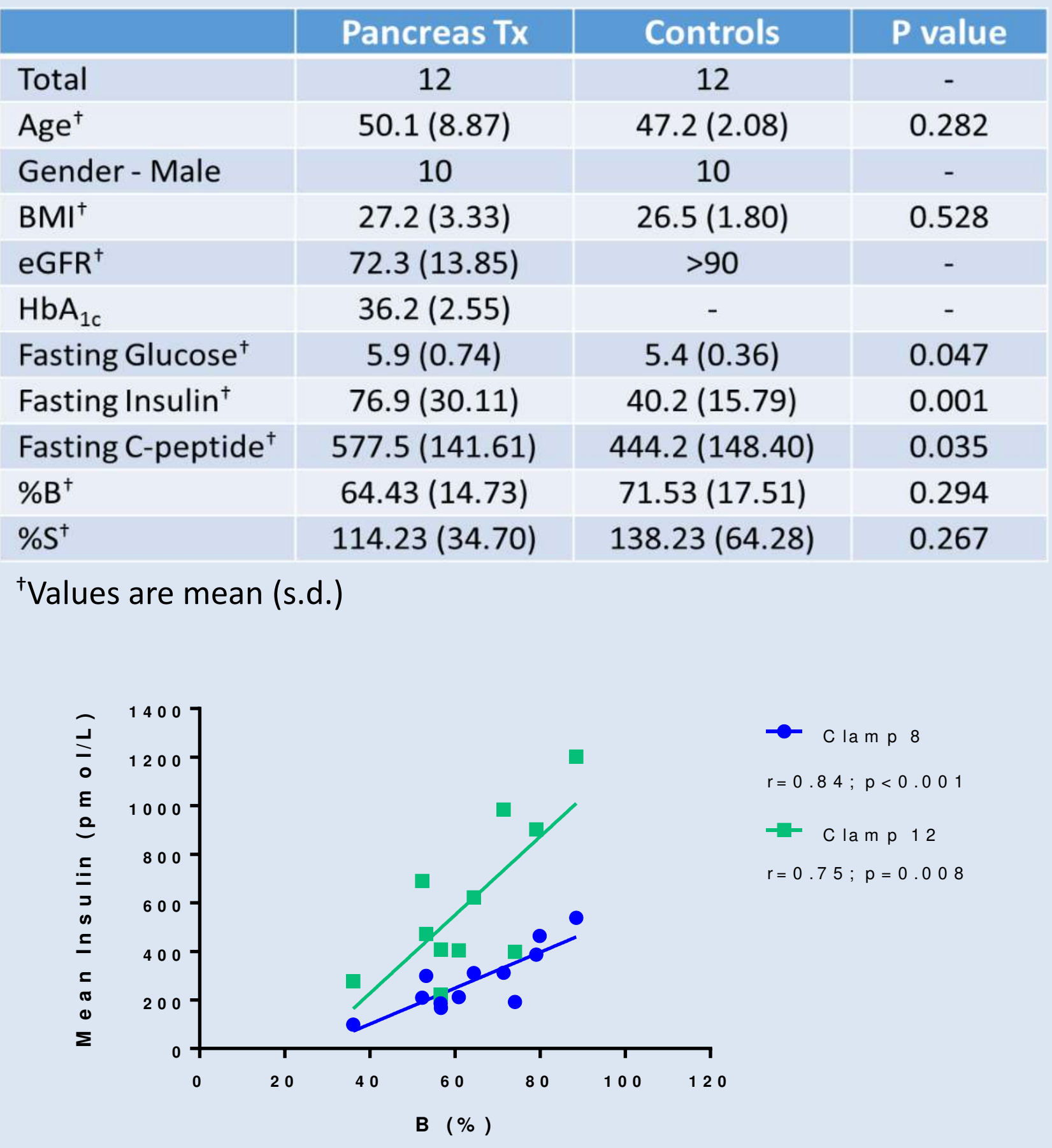

Figure 1: Correlation of $\% \mathrm{~B}$ and mean serum insulin in pancreas transplant recipients

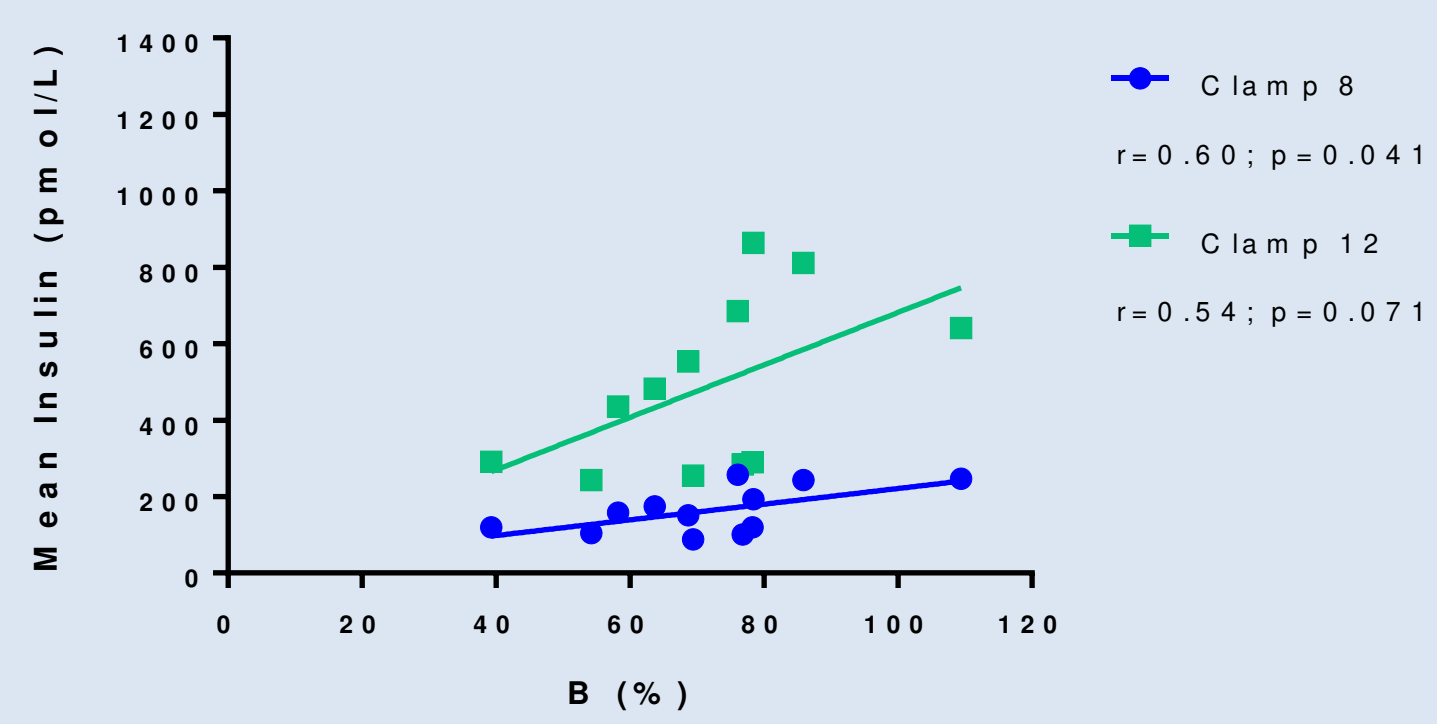

Figure 2: Correlation of \%B and mean serum insulin in matched controls

\section{CONCLUSIONS}

- HOMATx is the $1^{\text {st }}$ model developed for the assessment of pancreas graft function

- It is quick and simple to use

- Correlates well with directly measured function

- It may provide a useful tool for longitudinal graft monitoring 